\title{
Does the NIMBY strategy really promote a self-interest?: Evidence from England's waste management policy
}

\section{By}

\section{Masashi Yamamoto \\ Yuichiro Yoshida}

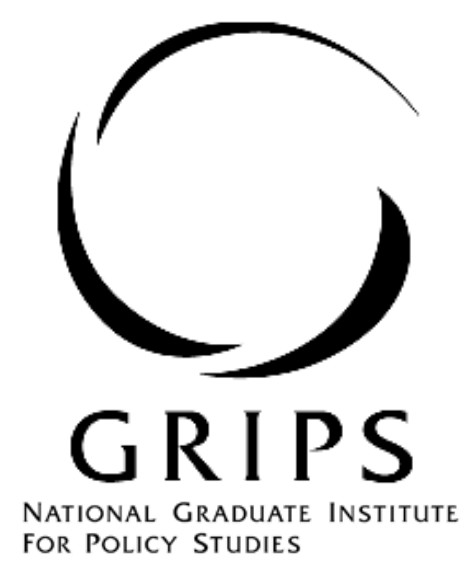

National Graduate Institute for Policy Studies

7-22-1 Roppongi, Minato-ku,

Tokyo, Japan 106-8677 


\title{
Does the NIMBY strategy really promote a self-interest?: Evidence from England's waste management policy*
}

\author{
Masashi YAMAMOTO $^{\dagger} \quad$ Yuichiro YOSHIDA Y $^{\ddagger}$
}

October 2012

\begin{abstract}
NIMBY (not in my backyard) is the word used to describe the human behavior whereby a person agrees on an issue but refuses to accept it when it happens 'in his own back yard'. This paper analyzes this type of NIMBY activity and, using evidence from England's waste management policy, determines that NIMBY decisions are not necessarily the result of personal self-interest. If people disagree with building a nuisance facility, such as a site for waste and recyclables, in their own backyard, the result is an increase in illegal dumping rather than the legal and proper disposal of waste materials at an official facility. Using the spatial econometrics approach, we further provide evidence that the broken window theory is also applicable to illegal dumping.
\end{abstract}

Key Words: Illegal Dumping, Spatial Econometrics, Waste Management, NIMBY problem

\section{Introduction}

Waste is and has always been a general byproduct of human life, and though waste materials surround us, they have not been considered a devastating pollution problem until recently. The status of waste materials and their impact on the environment, however, began to change with the onset of the era of mass production and consumption. Consider, for example, that each household is filled with electric devices and toxic chemicals, most of which are very costly and difficult to dispose of in a proper manner. While waste is one of the major sources of pollution in our society, the greatest pollution from waste is caused by illegal dumping. Consequently, the proper disposal of waste versus the illegal dumping of waste is one of the great concerns for many countries.

\footnotetext{
*This work was supported by the Grant-in-Aid for Young Scientists (B) (\#23730273).

${ }^{\dagger}$ Corrensponding Author. Associate Professor, Center for Far Eastern Studies, University of Toyama, 3190 Gofuku, Toyama, Japan 930-8555, Email: myam@eco.u-toyama.ac.jp, Tel: +81-76-445-6455.

${ }^{\ddagger}$ Associate Professor, National Graduate Institute for Policy Studies, 7-22-1 Roppongi, Minato-ku, Tokyo, Japan 106-8677, Email: yoshida@grips.ac.jp
} 
The USEPA (1998), for instance, addresses concerns about the illegal disposal of wastes and its impact on human health. Harmful fluids or dust generated by wastes can be harmful to people, especially children, who are often more vulnerable to physical and chemical hazards. In addition, the USEPA (1998) mentions the higher risks associated with the prevalence of mosquitoes that thrive in the stagnant waters found in scrap tires and waste dumps, as these insects carry severe diseases, such as dengue fever and encephalitis. In addition to the aforementioned risks of severe health problems, illegal dumping can also result in spontaneous combustion, which leads to property damage and possible neighborhood evacuations, and runoffs from the dump site, which often become the source of pollution in drinking water.

From the cost perspective, the impact of illegal dumping can also be quite substantial. The UK Environment Agency reports that "[i]t is estimated to cost $£ 100-£ 150$ million every year to investigate and clear up" illegal dumping. ${ }^{1}$ According to the Japanese Ministry of the Environment, a clean-up cost for one of the worst dump sites located on the border of the Aomori and Iwate prefectures is estimated to be 598 million Euro. In response to these situations, several countries are beginning to reexamine their regulations with respect to illegal dumping and are introducing more stringent rules and/or penalties for waste crimes. The UK's Defra, for example, has just launched tougher penalties against waste crimes, such as illegal dumping, ${ }^{2}$ while within the last decade, the Japanese government has repeatedly strengthened penalties for waste crimes as defined in the Waste Disposal and Public Cleansing Law.

Despite the impact of illegal dumping, the economics literature on the subject is rather limited. Among others, Sigman (1998), which examined the illegal dumping of used oil in the United States, is considered the seminal work in the field of illegal dumping. Our study, however, is much like Kim et al. (2008), who empirically examined the illegal dumping by households. ${ }^{3}$ Kim et al. (2008) argued that illegal dumping was induced

\footnotetext{
${ }^{1}$ http://www.environment-agency.gov.uk/homeandleisure/waste/flytipping/37851.aspx

${ }^{2}$ See the news release (http://www.defra.gov.uk/news/2008/080613a.htm) on July 13, 2008 for details.

${ }^{3}$ Apart from the empirical study, there are several theoretical studies that focus on illegal dumping, such as Fullerton and Kinnaman (1995).
} 
by the introduction of unit pricing of municipal solid waste in South Korea, and they concluded that authorities must, therefore, be careful about increasing unit prices.

Our research is motivated by Ichinose and Yamamoto (2011), who insisted that one of the main factors that induces illegal dumping is the shortage of proper waste treatment facilities. Accordingly, the present paper focuses on the consequences of the shortage of proper waste treatment facilities. Waste is generated in every household every day, regardless of the capacity of the waste treatment facilities, and this waste must be disposed of because it is not practical to keep it in the house for a number of reasons (e.g., unpleasant odor and lack of sufficient space). Our hypothesis is that legally avoiding the construction of a nuisance facility may reduce concerns regarding the negative impact on the aesthetics of the area but does not necessarily reduce other serious environmental effects, such as those from another illegal activity, such as illegal dumping. We posit that limiting the legal way to dispose of waste simply forces the proper disposal of certain wastes into illegal dumps. To verify this hypothesis, we introduce the theoretical result of Ichinose and Yamamoto (2011) and develop an econometric model.

Our second hypothesis is that there is a spatial correlation of fly tipping among local authorities. This type of spatial dependence is called the broken windows theory. As the USEPA (1998) states, “Dump sites serve as magnets for additional dumping and other criminal activity", a practice that is not new or uncommon. To the best of our knowledge, however, there is no statistical evidence available in the existing literature to support the USEPA's statement. To provide objective validity of the broken windows theory for illegal dumping, we use a spatial econometric approach.

Finally, the third hypothesis to be verified is that the less frequent collection of waste and recyclables increases illegal dumping. This notion is motivated by Abbott et. al (2011), who found evidence that " the lower the frequency of collection of residual waste, the higher the recycling rate." Considering whole waste management, there is a concern that disutility caused by lower collection frequency could promote more illegal dumping if the frequency of the waste collection is reduced to promote a higher recycling rate. Thus, we attempt to verify whether the less frequent collection of residual waste actually 
promotes illegal dumping. If so, the naive introduction of a less frequent collection policy must pay an unforeseen cost at the other end.

In the next section, we describe the simple economic model, and in Section 3, we explain the spatial econometric issues addressed in this paper. In Section 4, we present the data and estimated results along with the policy implications. Finally, in Section 5, we offer concluding remarks.

\section{The Model}

Suppose that there are $k$ identical households that discharge waste ${ }^{4}$. Each household generates $G$ amount of waste that must be disposed of. Once the waste is handed over to a disposing firm, it can be disposed of using an appropriate treatment process (denoted by $L$ ). The other choice is that a household dumps the waste illegally (= illegal dumping or fly tipping). The amount of illegal dumping is denoted by $m I$, which represents the number of illegal dumpings $(m)$ and the fixed amount of waste dumped per number of dumpings $(I)$. We assume that it $\operatorname{costs} c_{L}$ to properly dispose of the waste and $c_{I}$ to illegally dump $m I$ amount of waste. Here, $c_{L}$ includes the cost for the offensive smell or the cost for the space to keep the waste until collection, which, in some cases, only occurs once over a two-week period. Alternatively, $c_{L}$ could represent the cost for a household member to take the waste to the dumping site. In what follows, we assume that $c_{L}$ denotes the lowest cost for the aforementioned options.

Furthermore, we assume that illegal dumping would be punished if detected. Let $p(m I)$ with $p^{\prime}>0, p^{\prime \prime}>0$ be the probability of the environmental authority detecting the illegal dumping. Then, household $i$ faces the following problem:

$$
\begin{aligned}
\min _{L_{i}, m_{i}} & c_{L} L_{i}+c_{I} m_{i} I+p\left(m_{i} I\right) F, \\
\text { s.t. } & L_{i}+m_{i} I=G,
\end{aligned}
$$

where $F$ denotes the fine for illegal dumping. By minimizing (1) with the constraint, we

\footnotetext{
${ }^{4}$ The following model is based on Ichinose and Yamamoto (2011).
} 
obtain the demand function for the proper treatment of waste as follows:

$$
c_{L}-c_{I}-p^{\prime}\left(G-L_{i}\right) F=0
$$

Let $L_{i}^{d}$ be the household's demand for legal waste treatment; then, from (3), each household's demand function can be written as $L_{i}^{d}=l\left(c_{L}, c_{I}, G, F\right)$. Because we suppose that all firms are identical, the total demand for legal waste treatment is

$$
\sum_{i=1}^{k} L_{i}^{d}=k l\left(c_{L}, c_{I}, G, F\right) .
$$

If we now consider the disposing firms, each firm is also assumed to have the same supply function for the waste treatment service. That is, $L_{j}^{s}=f_{j}\left(c_{L}\right)$, where $j$ is the indicator for each disposing firm. We assume that $f_{j}(\cdot)$ is twice differentiable and that its first derivative is positive. As all of the disposing firms are homogeneous, the aggregate supply function can be written as follows:

$$
\sum_{j}^{n} L_{j=1}^{s}=n f_{j}\left(c_{L}\right) .
$$

where $n$ is the number of disposing firms. At equilibrium, $\sum_{i} L_{i}^{d}=\sum_{j} L_{j}^{s}$ must be satisfied. That is,

$$
k l\left(c_{L}^{*}, c_{I}, G, F\right)-n f\left(c_{L}^{*}\right)=0,
$$

must be met. Remember that our motivation is to analyze the relationship between illegal dumping and the provision of waste treatment sites. To focus on this relationship, we assume that $k=1$. Let $M$ denote the total number of illegal dumpings, namely, $M\left(n, c_{I}, G, F\right) \equiv \sum_{i} m\left(n, c_{I}, G, F\right)$. We then have the following results ${ }^{5}$ :

$$
\begin{aligned}
& \frac{d M}{d n}=\sum_{i} \frac{d m_{i}^{*}}{d n}<0 \\
& \frac{d M}{d c_{I}}=\sum_{i} \frac{d m^{*}}{d c_{I}}<0
\end{aligned}
$$

An increase in the number of waste treatment facilities $(=n)$ decreases the number of illegal dumpings. This result is closely related to (8), which confirms that a higher cost of illegal dumping decreases the number of illegal dumpings.

\footnotetext{
${ }^{5}$ For the derivation process, see the appendix of Ichinose and Yamamoto (2011).
} 
While illegal dumping could lead to one of the worst environmental pollution hazards due to its waste discharge, we expect no direct environmental damage from official waste treatment facilities. While there may be some indirect effects on property value or on the image of the communities where the facilities were built, the cost for the facilities was less than that of illegal dumping, which could result, in the worst-case scenario, in health problems. Nevertheless, communities often refuse to allow a waste and/or recycling treatment facility. We should note that this overreaction and refusal to allow a waste treatment site is not necessarily in the best own interest of the community.

Based on the results presented, we attempt to verify these theoretical results by applying econometric inference.

\section{Econometric Specification}

We first consider our hypotheses that there would be broken-window-theory-type behavior for illegal dumping. If so, there will be a bias when we apply the OLS method in our empirical analysis. We first determine whether there is any spatial dependency in the event of illegal dumping using Moran's I and the Lagrange multiplier test ${ }^{6}$. In this paper, we explore two types of spatial specifications: the spatial lag model and spatial error model.

Suppose that there exist $N$ regions in the data. The spatial lag model is

$$
y_{i}=\beta_{0}+\rho w_{i}^{L}+\beta_{1} x_{i}+\epsilon_{i},
$$

where the parameter $\rho$ is a spatial autocorrelation coefficient, and $w_{i}^{L}$ is $i$ th element of $W y$. Note that $W$ is $N \times N$ spatial weight matrix defined below and that $y$ is a vector of our dependent variables, that is, the number of illegal dumpings that occurred in a local authority. We also assume that $\epsilon_{i}$ is independently and identically distributed.

The other specification is the spatial error model, in which the spatial effect is derived through the error terms as follows:

$$
y_{i}=\beta_{0}+\beta_{1} x_{i}+\mu_{i}
$$

\footnotetext{
${ }^{6}$ See Anselin (2006) for detail.
} 
where

$$
\mu_{i}=\lambda w_{i}^{E}+\epsilon_{i}
$$

As in the spatial lag model, $w_{i}^{E}$ is the $i$ th element in vector $W \mu$, and the $\epsilon_{i}$ values are also assumed to be independent and identically distributed.

If the normality on the pure error term is satisfied, both models could be estimated using the maximum likelihood (ML) method. Unfortunately, the Jarque Bera tests for normality in both models conclude that the normality is not satisfied in our data; therefore, we no longer use the ML method. Rather, we apply the GM method, developed by Kelejian and Prucha (1999), to estimate the spatial lag model above, and we use the generalized two-stage least-squares method, developed by Kelejian and Prucha (1998), to estimate the spatial error model $^{7}$.

With respect to the spatial weight matrix (SWM), we apply two different SWMs to verify robustness. One is an SWM based on the queen-type contiguity, which considers any two local authorities as neighbors if the two local authorities share any boundary point. The other SWM considers distance-based neighbors, which assigns neighbors based on a specified distance. In this paper, the specified distance is the maximum difference between any two local authorities. With this definition, we have no local authority that has zero neighbors.

Figure 1 is the comparison of the links among neighbors in two different SWMs. As can be observed, the number of neighbors substantially increases in the SWM with respect to distance-based neighbors. Considering the nature of household behavior, we place greater emphasis on the queen-type contiguity when arguing the empirical results.

\section{Empirical Results}

\subsection{Data}

Our data for this research are collected from three databases. The data on fly tipping in England are from the database called Flycapture, on which local authorities record the details when they find an incident of fly-tipping. Flycapture data are publicly accessible

\footnotetext{
${ }^{7}$ These methods are available in spdep package in R. See chapter 10 of Bivand et al. (2008) for further information on computation issues.
} 

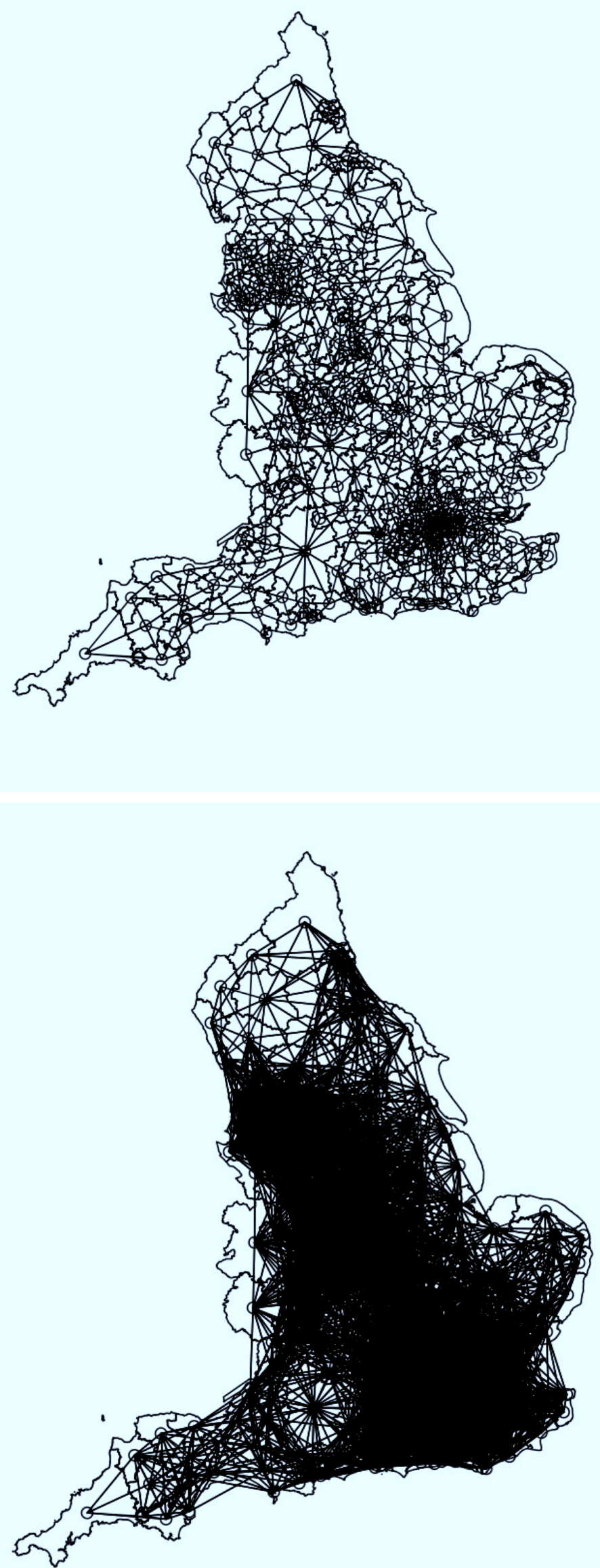

Figure 1: Comparison of two spatial weight matrix (above: Queen Type, below: Distance based 
and easy to download from the DEFRA website. In this database, the number of flytipping occurrences in each local authority is available. We use the data from 2010 to 2011 (the total number of occurrences in a year in each local authority).

We only use the most recent year's data because a breakdown of the fly-tipping data is only available for this year. In other years' data, we do not specify the ratio of household fly tipping in a local authority. We believe that this breakdown is critical because the behavioral mechanisms behind the household and industry are different. Mixing fly tipping by household and by industry could mislead us to an inappropriate conclusion. As our interest is on household activity, we only use the data on household fly tipping.

The second data source is Waste Data Flow ${ }^{8}$. All of the waste-related data except fly tipping are collected from this database. In addition, data on population, household and the deprivation index were also taken from this database. We use the data from the first quarter (January to March) of 2010 because there is likely to be a lag between an illegal dumping and its detection. Thus, we assume that the average time lag between the illegal disposal and the actual detection of fly tipping is half a year.

The last data source is the ONS shapefile data, which provide us with polygon files ${ }^{9}$. These data are indispensable for drawing a map at the level of the local authorities in the UK. As the polygon data contain information on borders, we can create a spatial weight matrix based on these data. In addition to creating a map, the area data that we use are also collected from this database.

Table 1 presents the descriptive statistics of our data. In Table 1, FThw is the number of fly tippings by household in each local authority during one year. DEFRA states that " flytipping is the common term used to describe waste illegally deposited on land as described under section 33 of the Environment Protection Act 1990.” For the purposes of recording on Flycapture, DEFRA also states that "waste should be counted as a flytip if it is too large to be removed by a normal hand-sweeping barrow." Figure 2 is a plot of FThw. Each dot on the map represents a local authority and corresponds to a dot on the graph. The emphasis on the first quadrant indicates the local authority with a higher

\footnotetext{
${ }^{8}$ This database is available at http://www. wastedataflow.org/.

${ }^{9}$ These data are available at http://www.ordnancesurvey.co.uk
} 
Table 1: Descriptive Statistics

\begin{tabular}{lrrrrr}
\hline & n & mean & \multicolumn{1}{c}{ sd } & \multicolumn{1}{c}{ min } & \multicolumn{1}{c}{ max } \\
\hline FThw & 323 & 1588 & 3705 & 61.00 & 50027 \\
ActionT & 323 & 1755 & 3290 & 0.00 & 36548 \\
hw & 323 & 8449 & 6444 & 0.00 & 57142 \\
pop & 323 & 157741 & 105724 & 8000 & 1010200 \\
HH & 323 & 65034 & 43283 & 5000 & 399000 \\
Area & 323 & 40837 & 56132 & 314.94 & 507835 \\
DI & 323 & 18.86 & 9.29 & 4.17 & 49.78 \\
SiteT & 323 & 61.51 & 66.45 & 0.00 & 534.00 \\
WCF & 323 & 0.33 & 0.47 & 0.00 & 1.00 \\
RCF & 323 & 0.15 & 0.36 & 0.00 & 1.00 \\
\hline
\end{tabular}

Source: Flycapture, Waste Data Flow and ONS data base

See main text for the explanation of variables.

level of illegal dumping in the local authority as well as the level of illegal dumping in the neighboring local authorities. It seems there is more fly tipping around the larger cities, but this may be because lower income households live near larger cities. To fully understand the spatial dependency of fly tipping, we must control any other effect as much as possible by introducing the proper variables.

One of these variable is ActionT, which is the number of actions taken by various local authorities against fly tipping in the previous year. This includes all of the recorded actions from simply leaving a warning to actual prosecution. In the empirical work, the number of actions taken divided by the total incidents (ActionR) is used. The total number of tons of waste collected from each local authority is denoted as HW, while SiteT denotes the total number of bring sites for wastes and recyclables ${ }^{10}$. In the empirical model, we use the total number of bring sites divided by the area (perST).

For waste collection, we use two variables. One is WCF, which is the dummy variable taking a value of one if the household waste is collected fortnightly or less often and a wheeler bin is small (10 to 150 little). The other variable is RCF, which takes a value of one if recyclables are collected fortnightly or less often and the recycling bin is less than 50 little.

\footnotetext{
${ }^{10}$ The recognition as NIMBY facility would be higher for other larger facilities like incinerators and landfill sites than the bring site. We, however, believe the bring site still has some negative externality effect for us and could be considered as nuisance facility for some residence.
} 

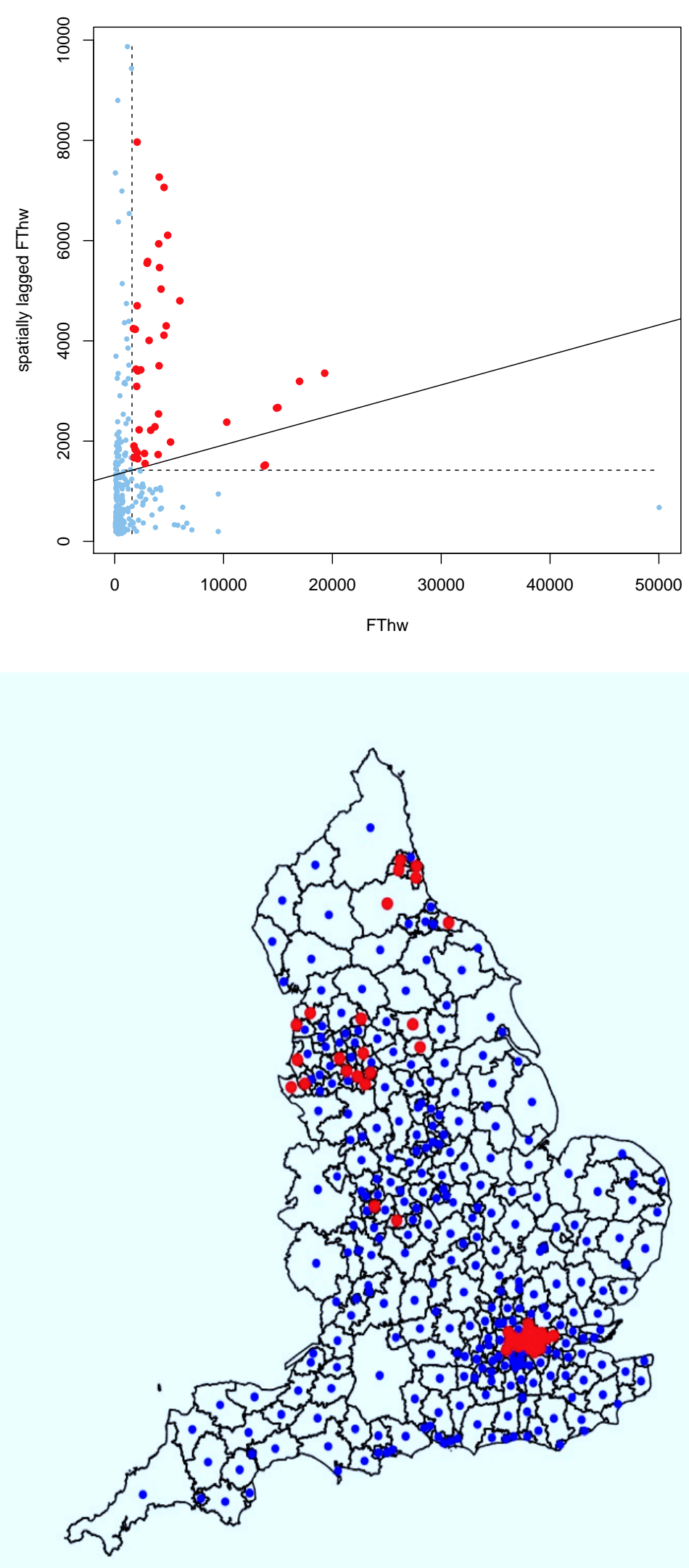

Figure 2: Fly Tipping in England (2010-11, household waste) 
In addition to the waste-related variables, we use the following socio-economic variables: Area for the area of each local authority in hectares, pop for the population of each local authority, and DI for the deprivation index score (2010) in each local authority.

\subsection{Estimation Results}

Table 2 shows the estimated results for the case with queen-type contiguity. First, the LM test result $\left(L M_{l a g}\right.$ and $\left.L M_{e r r}\right)$ based on OLS residuals supports the spatial lag model with $5 \%$ significance. Table 3 also shows almost all of the same results, though with a little weaker significance for a few of the variables. As the queen-type SWM is more likely to express household behavior, we concentrate on the results in Table 2.

Table 2: Estimated Results with queen type contiguity

\begin{tabular}{|c|c|c|c|c|c|c|}
\hline \multirow[b]{2}{*}{ Variable } & \multicolumn{2}{|c|}{ OLS } & \multicolumn{2}{|c|}{ Spatial Lag Model } & \multicolumn{2}{|c|}{ Spatial Error Model } \\
\hline & Coefficient & (Std. Err.) & Coefficient & (Std. Err.) & Coefficient & (Std. Err.) \\
\hline HW & $0.454496^{* *}$ & $(0.072232)$ & 0.424274 & $(0.279459)$ & $0.444411^{* *}$ & $(0.071404)$ \\
\hline ActionR & $-0.530163^{* *}$ & $(0.133942)$ & $-0.537529^{* *}$ & $(0.141959)$ & $-0.530883^{* *}$ & $(0.131745)$ \\
\hline perST & -4.502780 & $(2.770194)$ & $-4.483593^{*}$ & $(2.066723)$ & $-4.529023^{\dagger}$ & $(2.730648)$ \\
\hline WCF & 0.002196 & $(0.109930)$ & 0.045334 & $(0.096704)$ & 0.014129 & $(0.108625)$ \\
\hline $\mathrm{RCF}$ & $-0.257397^{\dagger}$ & $(0.140666)$ & $-0.234532^{\dagger}$ & $(0.127947)$ & $-0.253573^{\dagger}$ & (0.138691) \\
\hline popden & 0.039168 & $(0.054487)$ & 0.065435 & $(0.072717)$ & 0.053042 & $(0.054492)$ \\
\hline DI & $1.437075^{* *}$ & $(0.108963)$ & $1.402421^{* *}$ & $(0.153520)$ & $1.423884^{* *}$ & $(0.107379)$ \\
\hline Intercept & $-1.374552^{*}$ & $(0.593404)$ & $-4.079338^{*}$ & $(1.614520)$ & $-1.281286^{*}$ & $(0.588024)$ \\
\hline$\rho$ & - & - & $0.468057^{*}$ & (0.193016) & - & - \\
\hline$\lambda$ & - & - & - & - & 0.16337 & (1.1427) \\
\hline$L M_{e r r}$ & 0.4722 & & & & & \\
\hline$R L M_{e r r}$ & 1.3242 & & & & & \\
\hline$L M_{l a q}$ & $4.9778^{*}$ & & & & & \\
\hline$R L M_{l a g}$ & $5.8297^{*}$ & & & & & \\
\hline \multicolumn{7}{|c|}{$* * 1 \% * 5 \%{ }^{\dagger} 10 \%$} \\
\hline $\mathrm{N}$ & \multicolumn{2}{|c|}{323} & \multicolumn{2}{|c|}{323} & \multicolumn{2}{|c|}{323} \\
\hline $\mathrm{R}^{2}$ & \multicolumn{2}{|c|}{0.517} & \multicolumn{2}{|c|}{ - } & \multicolumn{2}{|c|}{ 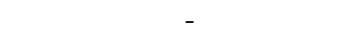 } \\
\hline $\mathrm{F}$ & \multicolumn{2}{|c|}{50.31} & \multicolumn{2}{|c|}{ - } & \multicolumn{2}{|c|}{ 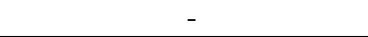 } \\
\hline
\end{tabular}

The results of the LM tests suggest that we must consider the spatial dependence and focus on the result of the middle of the spatial lag model. As the coefficient of the spatial lag $(=\rho)$ is also significant and positive, our hypothesis that the broken window theory is applicable to illegal dumping is confirmed. Note that we control the income level with the deprivation index even though there is still a spatial dependency among local authorities, which is robust evidence that one fly tipping event could certainly lead to another fly tipping event.

With respect to the hypothesis on collection frequency, the results are ambiguous in 
Table 3: Estimated Results with distance based contiguity

\begin{tabular}{|c|c|c|c|c|c|c|}
\hline \multirow[b]{2}{*}{ Variable } & \multicolumn{2}{|c|}{ OLS } & \multicolumn{2}{|c|}{ Spatial Lag Model } & \multicolumn{2}{|c|}{ Spatial Error Model } \\
\hline & Coefficient & (Std. Err.) & Coefficient & (Std. Err.) & Coefficient & (Std. Err.) \\
\hline $\mathrm{HW}$ & $0.454496^{* *}$ & $(0.072232)$ & 0.400554 & $(0.276542)$ & $0.430717^{* *}$ & $(0.071497)$ \\
\hline ActionR & $-0.530163^{* *}$ & $(0.133942)$ & $-0.595235^{* *}$ & $(0.150469)$ & $-0.554512^{* *}$ & $(0.130844)$ \\
\hline perST & -4.502780 & $(2.770194)$ & $-3.468262^{\dagger}$ & $(1.881782)$ & -4.450508 & $(2.768791)$ \\
\hline WCF & 0.002196 & $(0.109930)$ & 0.061672 & $(0.095788)$ & 0.017240 & $(0.108040)$ \\
\hline RCF & $-0.257397^{\dagger}$ & $(0.140666)$ & $-0.273400^{*}$ & $(0.125857)$ & $-0.278180^{*}$ & $(0.138602)$ \\
\hline popden & 0.039168 & $(0.054487)$ & 0.058600 & $(0.071283)$ & 0.055460 & $(0.055034)$ \\
\hline DI & $1.437075^{* *}$ & $(0.108963)$ & $1.379371^{* *}$ & $(0.138355)$ & $1.433877^{* *}$ & $(0.108496)$ \\
\hline Intercept & $-1.374552^{*}$ & $(0.593404)$ & $-2.656859^{\dagger}$ & $(1.476381)$ & $-1.179486^{*}$ & $(0.589288)$ \\
\hline$\rho$ & - & - & $0.294735^{\dagger}$ & $(0.15677)$ & - & - \\
\hline$\lambda$ & - & - & - & - & 0.11402 & $(0.20213)$ \\
\hline$L M_{e r r}$ & 1.7391 & & & & & \\
\hline$R L M_{e r r}$ & 0.4096 & & & & & \\
\hline$L M_{l a g}$ & $4.8522^{*}$ & & & & & \\
\hline$R L M_{l a g}$ & $3.5227^{\dagger}$ & & & & & \\
\hline \multicolumn{7}{|c|}{$* * 1 \% * 5 \%{ }^{\dagger} 10 \%$} \\
\hline $\mathrm{N}$ & \multicolumn{2}{|c|}{323} & \multicolumn{2}{|c|}{323} & \multicolumn{2}{|c|}{323} \\
\hline $\mathrm{R}^{2}$ & \multicolumn{2}{|c|}{0.517} & & \multirow{2}{*}{\multicolumn{2}{|c|}{$\begin{array}{l}- \\
-\end{array}$}} \\
\hline $\mathrm{F}$ & \multicolumn{2}{|c|}{50.31} & & & & \\
\hline
\end{tabular}

that waste collection is not significant, whereas the collection frequency of recyclables is significant and negative. According to the former finding, we could say that collection frequency is not relevant to illegal dumping, while from the latter result, we could conclude that illegal dumping is reduced when recyclables are collected on a more frequent basis. As Abbott et. al (2011) show, the decreasing collection frequency of waste increases the recycling rate. In other words, we can conclude from this result that reducing waste collection frequency does not promote illegal dumping. This finding is contrary to our hypothesis, though it yields better results when we consider a whole waste management policy because a policy that attempts to increase the recycling rate does not negatively impact the attempt to reduce illegal dumping.

Finally, the results show that the coefficient of perST is significant and negative, suggesting that illegal dumping increases if there is not a sufficient number of waste/recyclable treatment facilities in a local authority. From our perspective, the results suggest that people who adopt the NIMBY behavior must pay the price from the other end. Refusing to allow a waste/recyclable treatment site generates illegal dumping "in your back yard". This evidence is important as policy makers attempt to persuade those communities that are opposed to the building of a treatment facility. 


\section{Conclusion}

In this paper, we showed that NIMBY activity does not always benefit one's self-interests as it relates to fly tipping in England. Legally avoiding the construction of a nuisance facility may reduce concerns about the community's positive image, but it does not necessarily reduce other serious environmental effects from illegal activity, such as fly tipping. Policy makers and ordinary citizens should keep this in mind so that NIMBYtype behaviors do not cause further environmental damage.

We also revealed that there is a spatial correlation regarding the number of fly tipping events in local authorities, even after controlling for income levels in each local authority. This finding indicates that the broken window theory is applicable to illegal dumping. An earlier and effective measure against illegal dumping is the key to minimizing the costs associated with illegal dumping because illegal dumping produces more and more illegal activity once it prevails. 


\section{References}

Abbott, A., Nandeibam, S. and L. O'Shea (2011) "Explaining the variation in household recycling rates across the UK," Ecological Economics, viol. 70, pp. 2214 - 2223.

Anselin, L. (2006) "Chapter 26 Spatial Econometrics," in Mills and Patterson eds. (2006) Palgrave Handbook of Econometrics, Volume 1: Econometric Theory, Palgrave Macmillan.

BBC (2011) "Fly-tipping 'costs taxpayers $£ 40 \mathrm{~m}$ a year', " 1st September, available at http://www.bbc.co.uk/news/uk-14735213.

Bivand, R.S., Pebesma, E.J., and V. Gómez-Rubio (2008) Applied Spatial Data Analysis with $R$, Springer.

Dijkstra, B. and P. G. Fredriksson (2010) "Regulatory Environmental Federalism," Annual Review of Resource Economics, vol. 2, pp. 319- 339.

Fullerton, D. and Kinnaman, T.C (1995). "Garbage, Recycling, and Illicit Burning or Dumping," Journal of Environmental Economics and Management, vol. 29, no.1, pp. 78-91.

Ichinose, D. and M. Yamamoto (2011) "On the Relationship Between Provision of Waste Management Service and Illegal Dumping," Resource and Energy Economics, vol. 33, pp. 79-93, 2011.

Kelejian, H. H., and Prucha, I. R. (1999) "A Generalized Moments Estimator for the Autoregressive Parameter in a Spatial Model," International Economic Review, vol. 40, pp.509-533.

Kelejian, H.H. and Prucha, I.R. (1998) "A generalized spatial two stage least squares procedure for estimating a spatial autoregressive model with autoregressive disturbances," Journal of Real Estate Finance and Economics, vol. 17, pp. 99-121.

Kim, G.-S., Chang, Y.-J., and Kelleher, D. (2008). "Unit Pricing of Municipal Solid Waste 
and Illegal Dumping: An Empirical Analysis of Korean Experience," Environmental Economics and Policy Studies, vol. 9, pp. 167-176.

Kinnaman, T. (2009) "The economics of municipal solid waste management," Waste Management, vol. 29, pp. 2615-2617.

Levinson, A. (1999) "NIMBY taxes matter: the case of state hazardous waste disposal taxes," Journal of Public Economics, vol. 74, pp. 31 - 51.

Levinson, A. (1999) "State Taxes and Interstate Hazardous Waste Shipment," American Economic Review, vol. 89, .no. 3, pp. 666 -677.

Sigman, Hilary (1998) "Midnight dumping: public policies and illegal disposal of used oil," RAND Journal of Economics, vol. 29, no. 1.

Smithers, R. (2010) "Return to weekly rubbish collection 'would damage UK recycling'," The Guardian, Tuesday 28 September.

USEPA(1998) Illegal Dumping Prevention Guidebook, EPA905-B-97-001.

Waste Data Flow (2011) data available at www.wastedataflow.org

WYG Environment (2011) Review of Kerbside Recyling Collection Schemes in the UK in 2009/10. 